Article

\title{
Monitoring Global Croplands with Coarse Resolution Earth Observations: The Global Agriculture Monitoring (GLAM) Project
}

Inbal Becker-Reshef ${ }^{1, *}$, Chris Justice ${ }^{1}$, Mark Sullivan ${ }^{1}$, Eric Vermote ${ }^{1}$, Compton Tucker ${ }^{2}$, Assaf Anyamba ${ }^{2}$, Jen Small ${ }^{2}$, Ed Pak ${ }^{2}$, Ed Masuoka ${ }^{2}$, Jeff Schmaltz ${ }^{2}$, Matthew Hansen ${ }^{3}$, Kyle Pittman $^{3}$, Charon Birkett ${ }^{4}$, Derrick Williams ${ }^{5}$, Curt Reynolds ${ }^{5}$ and Bradley Doorn ${ }^{6}$

1 Geography Department, University of Maryland, College Park, MD 20742, USA; E-Mails: justice@hermes.geog.umd.edu (C.J.); mbs@hermes.geog.umd.edu (M.S.); eric@ltdri.org (E.V.)

2 NASA Goddard Space and Flight Center (GSFC), Greenbelt, MD 20771, USA; E-Mails: Compton.j.tucker@nasa.gov (C.T.); Asaph.anyamba-1@nasa.gov (A.A.); jennifer.l.small@nasa.gov (J.S.); Edwin.w.pak@nasa.gov (E.P.); Edward.j.masuoka@nasa.gov (E.M.); jeff.schmaltz@nasa.gov (J.S.)

3 Geographic Information Science Center of Excellence, South Dakota State University, Brookings, SD 57007, USA; E-Mails: matthew.hansen@sdstate.edu (M.H.); kyle.pittman@sdstate.edu (K.P.)

4 Earth System Science Interdisciplinary Center (ESSIC) University of Maryland Research Park (M-Square), College Park, MD 20742, USA; E-Mail: cmb@essic.umd.edu

5 Foreign Agricultural Service, US Department of Agriculture, Washington, DC 20250, USA; E-Mails: derrick.williams@fas.usda.gov (D.W.); curt.reynolds@fas.usda.gov (C.R.)

6 NASA Head Quarters, Washington, DC 20546-0001, USA; E-Mail: bradley.doorn@nasa.gov

* Author to whom correspondence should be addressed; E-Mail: ireshef@hermes.geog.edu; Tel.: +1-301-405-7954; Fax: +1-301-405-6806.

Received: 19 April 2010; in revised form: 7 June 2010 / Accepted: 8 June 2010 / Published: 18 June 2010

Abstract: In recent years there has been a dramatic increase in the demand for timely, comprehensive global agricultural intelligence. Timely information on global crop production is indispensable for combating the growing stress on the world's crop production and for securing both short-term and long-term stable and reliable supply of food. Global agriculture monitoring systems are critical to providing this kind of intelligence and global earth observations are an essential component of an effective global 
agricultural monitoring system as they offer timely, objective, global information on croplands distribution, crop development and conditions as the growing season progresses. The Global Agriculture Monitoring Project (GLAM), a joint NASA, USDA, UMD and SDSU initiative, has built a global agricultural monitoring system that provides the USDA Foreign Agricultural Service (FAS) with timely, easily accessible, scientifically-validated remotely-sensed data and derived products as well as data analysis tools, for crop-condition monitoring and production assessment. This system is an integral component of the USDA's FAS Decision Support System (DSS) for agriculture. It has significantly improved the FAS crop analysts' ability to monitor crop conditions, and to quantitatively forecast crop yields through the provision of timely, high-quality global earth observations data in a format customized for FAS alongside a suite of data analysis tools. FAS crop analysts use these satellite data in a 'convergence of evidence' approach with meteorological data, field reports, crop models, attaché reports and local reports. The USDA FAS is currently the only operational provider of timely, objective crop production forecasts at the global scale. These forecasts are routinely used by the other US Federal government agencies as well as by commodity trading companies, farmers, relief agencies and foreign governments. This paper discusses the operational components and new developments of the GLAM monitoring system as well as the future role of earth observations in global agricultural monitoring.

Keywords: agriculture; monitoring; MODIS; croplands; GLAM

\section{Introduction}

Global agricultural production faces increasing pressure from more frequent and extreme weather events such as floods, droughts and frosts; changes in the amounts, seasonality, intensity and distribution of precipitation; rising energy costs; civil conflicts; continued population growth (despite a decrease in the global growth rate); a growing meat demand from an expanding middle class; and land degradation [1]. Increasing competition for water is placing pressure on irrigation systems and poverty and conflict continue to undermine food security, particularly in the developing world [2]. Although global agricultural production output continues to grow, these pressures place increasing strain on society's ability to provide an adequate and safe supply of food for an increasing global population.

In response to the growing stress on world food supplies, the past few years have seen an increased demand for timely, comprehensive, transparent, and accurate global agricultural intelligence. Global agricultural trade, effective national and international agricultural policies, and timely response to food crises, depend on reliable and timely crop production information. Currently there are a large number of operational national and international agricultural monitoring systems operating at a range of scales providing critical agricultural information. The primary international monitoring systems include the USAID Famine Early Warning System (FEWS-NET), the UN Food and Agriculture Organization (FAO) Global Information and Early Warning System (GIEWS), the Monitoring Agriculture by Remote Sensing (MARS) Project of the European Commission, at the Joint Research Center (JRC 
Ispra), the Crop Watch Program at the Institute of Remote Sensing Applications (IRSA) of the Chinese Academy of Sciences and the USDA Foreign Agricultural Service (FAS) Global Agriculture Monitoring (GLAM) System.

The USDA FAS is currently the only provider of regular, timely, objective crop production forecasts at the global scale. This unique capability is in part afforded by the USDA's partnership with NASA through the GLAM project, which provides global coverage of earth observations data and analysis tools for crop condition monitoring and production assessment at the global scale [3].

\subsection{NASA USDA Partnership}

The National Aeronautics and Space Administration (NASA) and the US Department of Agriculture (USDA) have been working together to monitor global agriculture from space since the 1970s. Preliminary research and development on satellite monitoring of agriculture started with the ERTS (Landsat system) in the early 1970's. Key events, including unanticipated severe wheat shortages due to Russian crop failure, drew attention to the importance of timely and accurate prediction of world food supplies. As a result in 1974, the USDA, NASA and National Oceanic and Atmospheric Administration (NOAA) initiated the Large Area Crop Inventory Experiment (LACIE) [4]. The goal of this experiment was to improve domestic and international crop forecasting methods [5]. Earlier work by USDA researchers in the late sixties and early seventies on relating crop plants to their optical properties [6-8] provided the theoretical basis for monitoring crop growth using remotely sensed information [5,9]. With enhancements that became available from the NOAA Advanced Very High Resolution Radiometer (AVHRR) sensor on board the Polar Operational Environmental Satellite (POES) allowing for daily global monitoring, and based on the success of the LACIE experiment that demonstrated satellite imagery could be used operationally to forecast wheat yields in the US and USSR [10], the Agriculture and Resource Inventory Surveys Through Aerospace Remote Sensing (AgRISTARS) program was initiated in the early 1980's jointly by NASA, USDA, NOAA and the US Department of State. Through the research conducted in these NASA-USDA joint programs the considerable potential for use of remotely sensed information for monitoring and management of agricultural lands was identified. One of the most recent efforts that NASA and the USDA Foreign Agricultural Service (FAS) have initiated is the Global Agricultural Monitoring (GLAM) Project focused on applying data from NASA's flagship instrument Moderate Resolution Imaging Spectroradiometer (MODIS) on board the Earth Observing System (EOS) Terra satellite to the feed FAS Decision Support System (DSS) needs.

\subsection{FAS Mission and Goals}

The Foreign Agricultural Service (FAS) of the US Department of Agriculture (USDA) works to improve foreign market access for US products, build new markets, improve the competitive position of US agriculture in the global marketplace, and provide food aid and technical assistance to foreign countries [11].

FAS has the primary responsibility for USDA's international activities, market development, trade agreements and negotiations, and the collection and analysis of statistics and market information. It also administers USDA's export credit guarantee and food aid programs, and helps increase income 
and food availability in developing nations by mobilizing expertise for agriculturally led economic growth [12].

The mission of the FAS Office of Global Analysis (OGA)/International Production Assessment Division (IPAD) is to produce the most objective and accurate assessment of the global agricultural production outlook and the conditions affecting food security in the world. To successfully carry out this objective it is essential to gather, archive, analyze and disseminate objective, timely, comprehensive, reliable, global and cost-effective information on crop condition and production.

In order to accomplish this complex task, the OGA/IPAD of the FAS operates a sophisticated Decision Support System (DSS). This DSS consists of Crop condition Data Retrieval and Evaluation (CADRE) database management system, and Crop Explorer- a web based suite of decision support tools. This DSS provides FAS crop analysts the data and tools necessary for implementing a convergence of evidence approach to forecasting crop production. Using the DSS, the FAS crop analysts provide estimates of global production in support of the World Agricultural Outlook Board (WAOB) who coordinates, reviews and approved the monthly World Agricultural Supply and Demand Estimates (WASDE) report by the 11th day of each month. These estimates are routinely used by other Federal government agencies including the US Office of Management and Budget (OMB), Congress, the State Department, the US Agency for International Development (USAID), and the Office of Foreign Disaster Assistance (OFDA) as well as by commodity trading companies, farmers, relief agencies and foreign governments. These production estimates play a vital role within the global agricultural market as they are utilized in a variety of ways including: official USDA statistics, principal federal economic indicators, crop condition and early warning alerts, agricultural monitoring and food security, foreign aid assessments for food import needs, disaster monitoring and relief efforts related to food aid, commercial market trends and analysis, and trade policy and exporter assistance.

The crop annalist production estimates are derived by synthesizing information from a wide array of sources, including attaché reports, local reports, field surveys, climate data, and exploiting a variety of tools such as crop models and data visualization utilities. However, it is the remotely sensed earth observations that enable production forecasts to be comprehensive, global, unbiased, timely and cost-effective. Satellite data have played an important role in the FAS DSS system since the mid 1970s, providing timely, synoptic information on crop distribution and condition [13]. FAS is one of the largest users of remotely sensed data in the Federal Government utilizing a combination of Landsat, AWiFS, AVHRR, SPOT and MODIS data for operational monitoring of agriculture worldwide.

\section{GLAM}

GLAM is a joint research project between the USDA FAS, the Global Inventory Monitoring and Modeling Studies (GIMMS) group at NASA Goddard Space Flight Center (GSFC), the University of Maryland (UMD) Department of Geography and the Geographic Information Science Center of Excellence at South Dakota State University (SDSU). It was initiated in 2002 and is funded jointly by USDA-FAS and the NASA Science Applications Program. The GLAM project aims to enhance the agricultural monitoring and the crop-production estimation capabilities of the FAS using the new generation of NASA satellite observations, building one of the most comprehensive data management systems for remotely-sensed based global agricultural monitoring [14]. 
The system currently includes a customized web-based information-analysis and data-delivery system combining the capabilities of GIMMS Advanced Very High Resolution Radiometer (AVHRR) system, SPOT Vegetation, the MODIS Advanced Processing System (MODAPS), the MODIS Rapid Response System and the new NASA Land and Atmosphere Near real-time (LANCE) system. This system currently provides FAS crop analysts with AVHRR Global Area Coverage (GAC) data (1981-present), SPOT Vegetation (1998-present), MODIS vegetation indices (2000-present) and MODIS Rapid Response (250 m-imagery within 2-4 hours of overpass). GLAM is also working on new products custom-designed to meet FAS needs, including a dynamic, interactive global croplands likelihood map at $250 \mathrm{~m}$ resolution, and remote sensing- based seasonal metrics. The GLAM system, through its web-based technology, analysis tools, and NASA datasets, has improved the USDA FAS's operational capabilities to monitor global crop production and has become the primary tool that FAS analysts turn to for monitoring crops and for forecasting yield and production of the major crops grown worldwide [15]. The extensive web-accessible Database Management System (DBMS) provides a substantial platform on which to build a range of applications requiring frequent, timely, global moderate resolution data.

The GLAM project builds on NASA's investment in the calibration of the MODIS instrument and the development and validation of science products for transitioning NASA research to USDA operations. Future transition plans include expanding the capability to fuse coarse and moderate resolution satellite data and preparing the system for data from instruments planned for the National Polar-orbiting Environmental Satellite System (NPOESS) Visible Infrared Radiometer Suite (VIIRS) and the Landsat Data Continuity Mission (LDCM). The GLAM Project is also a contributor to the larger Group on Earth Observations (GEO) Global Agricultural Monitoring System of Systems (GLAMSS) effort.

The current GLAM project activities include: (1) Database Management System for MODIS composite vegetation indices and customized analysis tools (2) MODIS near real time data (3) Long Term archive of time-series VI data (4) and Operational Research and Development.

\subsection{GLAM DBMS and Tools}

A customized data archiving, processing, and delivery system that utilizes internet geographic information system (GIS) technology was developed according to FAS crop analyst needs. This system provides the FAS analysts with a series of global MODIS science Vegetation Index (VI) time-series data sets and corresponding archives at $250 \mathrm{~m}$ resolution. These data are reprojected and composited for FAS specified regions of interest. Through a web interface, FAS analysts are able to drill down to pixel level detail to better characterize land surface conditions and monitor changes in the key agricultural areas.

Currently 16-day composited Normalized Difference Vegetation Index (NDVI) and Normalized Difference Water Index (NDWI) and false color composite time-series data derived from the MODIS Standard Land Products Surface Reflectance are provided to FAS via the FAS CropExplorer web interface. The algorithms used in generating the MODIS Standard Products are described in the MODIS ATBD's (http://edcdaac.usgs.gov/modis/dataprod.html). The VI products are generated from aerosol corrected Land Surface Reflectance data [16]. New data are available every 8 days, as phased 16-day composite data sets are provided from both the Terra and Aqua sensors. The delivery of these 
science products into the FAS system varies from three days to twelve days behind the last date of acquisition. An additional 8-day composite dataset has been developed and will also be available to crop analysts through Crop Explorer. In addition to the time-series data sets, a variety of crop masks and water masks are available in order to spatially filter regional NDVI time-series data. Complementing these data products is a range of web-based analysis tools that allow analysts to interrogate the database to visualize and produce various metrics for evaluation of growing season conditions for different regions around the world. Using these data and tools, analysts track the evolution of the growing season, make inter-annual comparisons of seasonal dynamics and inform decision makers of agricultural conditions and impediments to worldwide food-security. The system's data streams and tools are integrated into CADRE and Crop Explorer and serve as an integral component to the USDA's DSS for agriculture monitoring. Figure 1 provides an example of how the GLAM MODIS DBMS was used to track the impact of the 2008-2009 drought on crops in Argentina. This drought had a devastating effect on crops leading to a 30-60 percent reduction in production relative to the previous year [17].

Figure 1. Example of utility of the GLAM MODIS NDVI DBMS to track 2009 drought impact on crops in Buenos Aires district in Argentina.

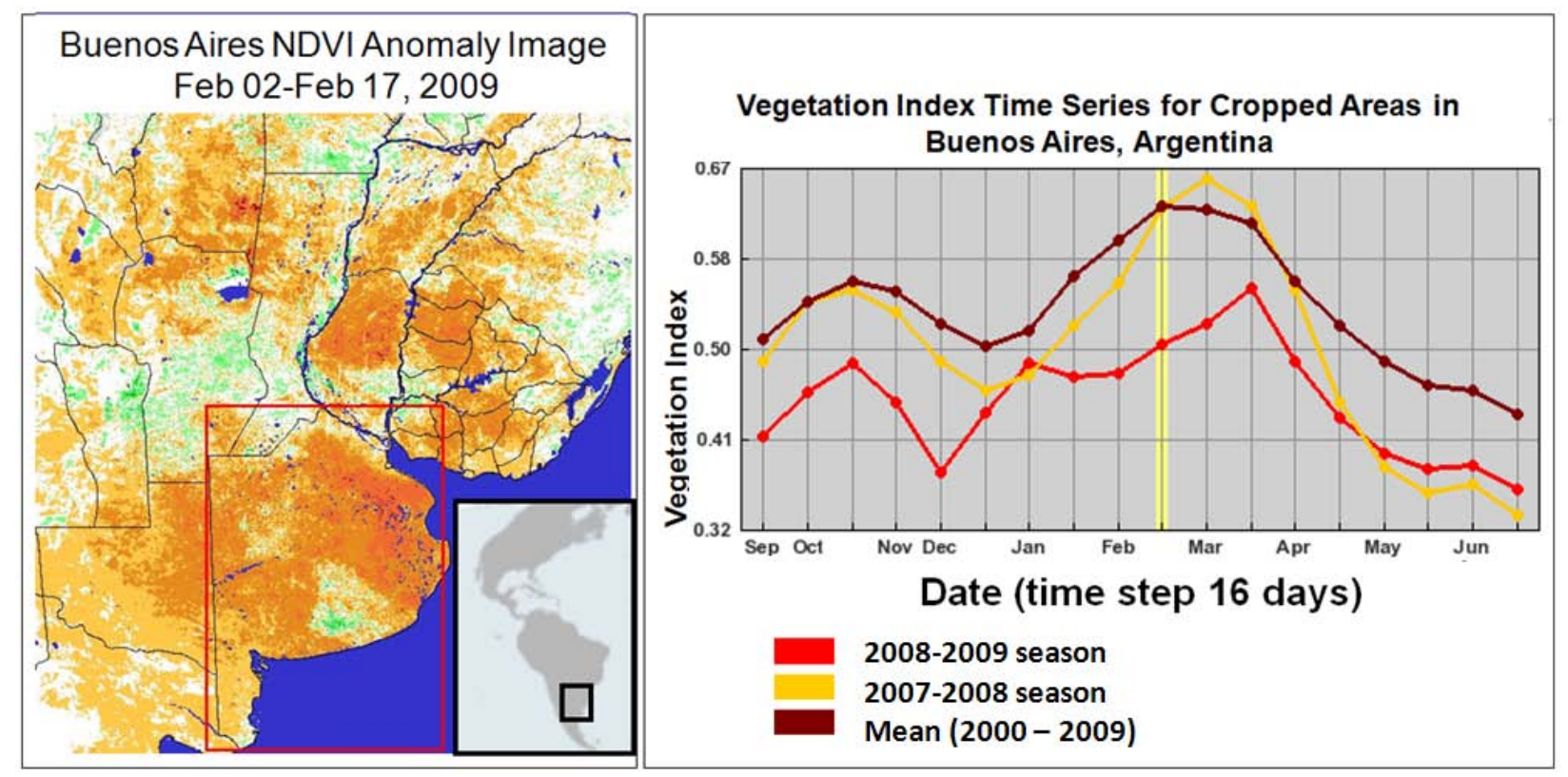

\subsection{MODIS Rapid Response}

The MODIS Rapid Response (RR) System provides FAS with near real-time daily, global, corrected-reflectance imagery [18] (http://rapidfire.sci.gsfc.nasa.gov/). The imagery includes true and false color composite products (using short wave infrared, near infrared and red bands) and a NDVI product, tailored to meet the FAS requirements. These products are available at three different spatial resolutions: 2 kilometer, 1 kilometer and 250 meter and are provided twice daily from the Terra satellite in the morning (10:30 am overpass) and from the Aqua satellite in the afternoon (2:30 pm overpass). The rapid turnaround, 2 to 4 hours after acquisition, enables FAS analysts to rapidly assess the impact to crops caused by weather related stress events or natural disasters. These data and tools have been integrated seamlessly into the FAS's Crop Explorer system making the imagery promptly 
available to the FAS analysts within their own operational environment (Figure 2). Currently, these data are used primarily for visual interpretation of ground conditions. For example, when the Tropical Storm Nargis devastated Myanmar in May of 2008, FAS analysts were able to immediately examine the extent and impact of the storm on croplands using the MODIS Rapid Response system (Figure 3).

Figure 2. MODIS Rapid Response Interface in Crop Explorer.

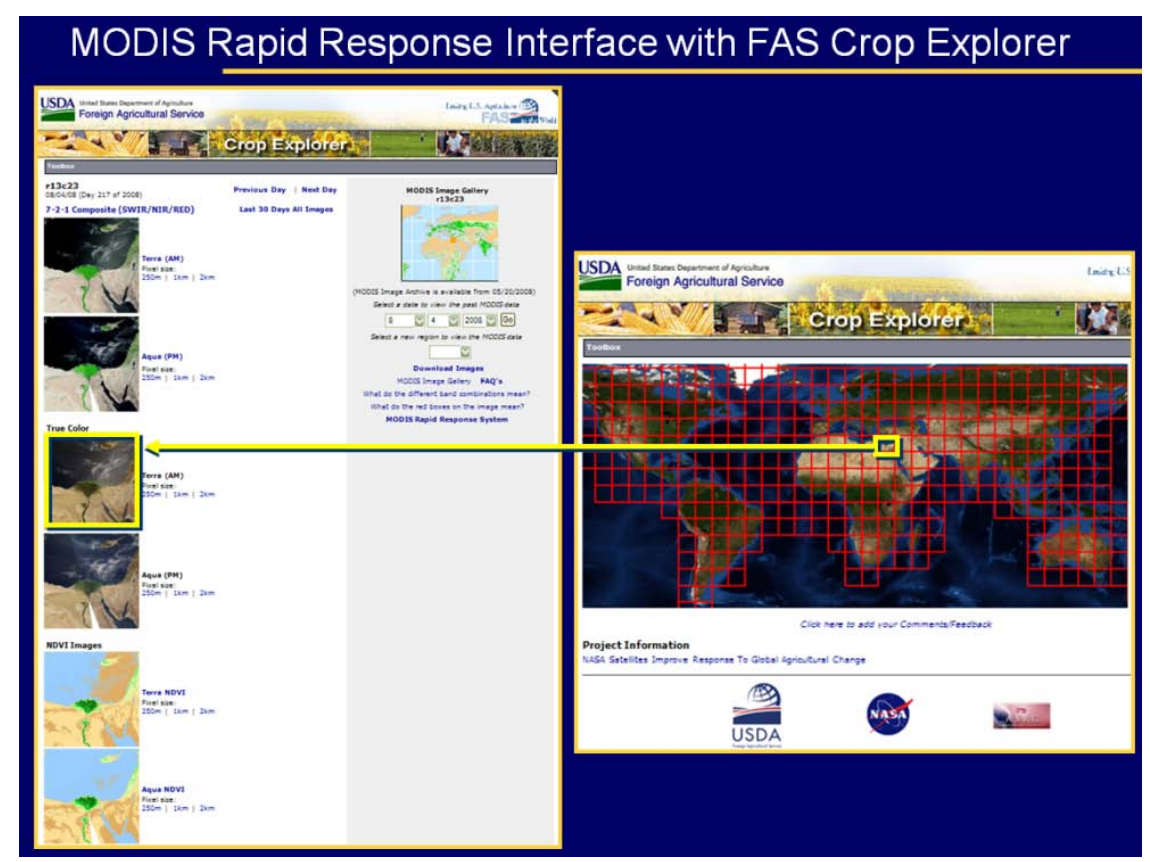

Figure 3. Using MODIS Rapid Response Imagery to Assess Impact of Tropical Storm Nargis, 2008.

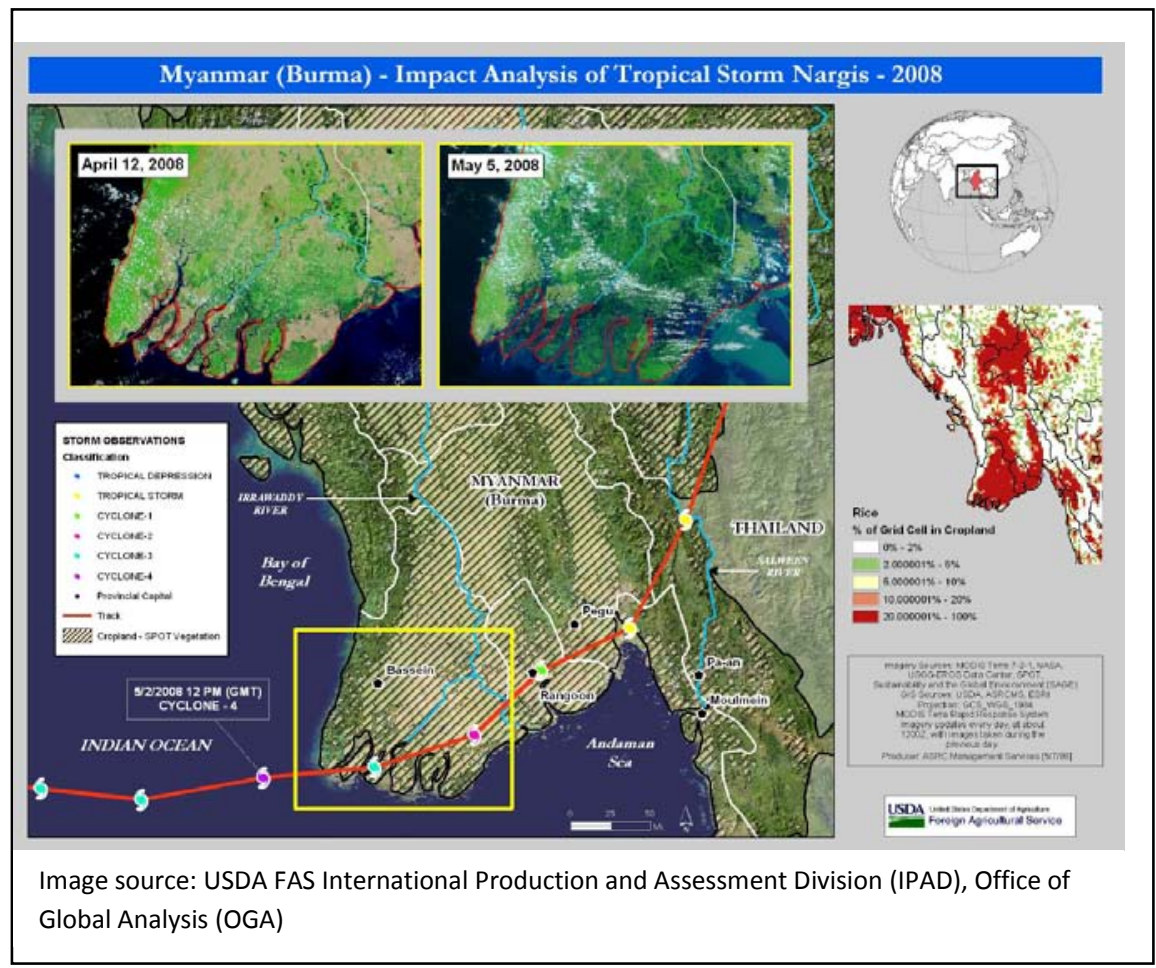




\subsection{Long Term Data Archive}

Another critical component of this program is the multi-source long-term Global NDVI archive. Data sources include the 8km AVHRR-VIg archive [19], which includes data from all NOAA AVHRR instruments from 1981 to present, the $8 \mathrm{~km}$ AVHRR-N17 product which uses data from the NOAA-17 AVHRR only (September 2002-present), and the $1 \mathrm{~km}$ SPOT-Vegetation NDVI data set (1998-present). While these data sets are of a coarse resolution, they provide a reference for long-term changes in vegetation conditions relevant for monitoring the impacts of climate variability and trends globally. In addition, the availability of these different streams of vegetation index data guarantee redundancy in the FAS DDS both for data inter-comparison and in case any of the remote sensing instruments fail or malfunction. Experience has shown that in an operational environment the availability of multiple sources of data is mission critical.

To ensure data continuity and redundancy, a global 1-km AVHRR NDVI product derived from the EUMESAT MetOp satellite series is being developed. The MetOp platforms are expected to provide continuing NOAA AVHRR coverage with a 9:30 am overpass through 2020.

Figure 4. Example of near real time NDVI anomaly products for Africa. Data sources clockwise from upper left: AVHRR-VIg, AVHRR-N17, MODIS Terra, SPOT-Vegetation.

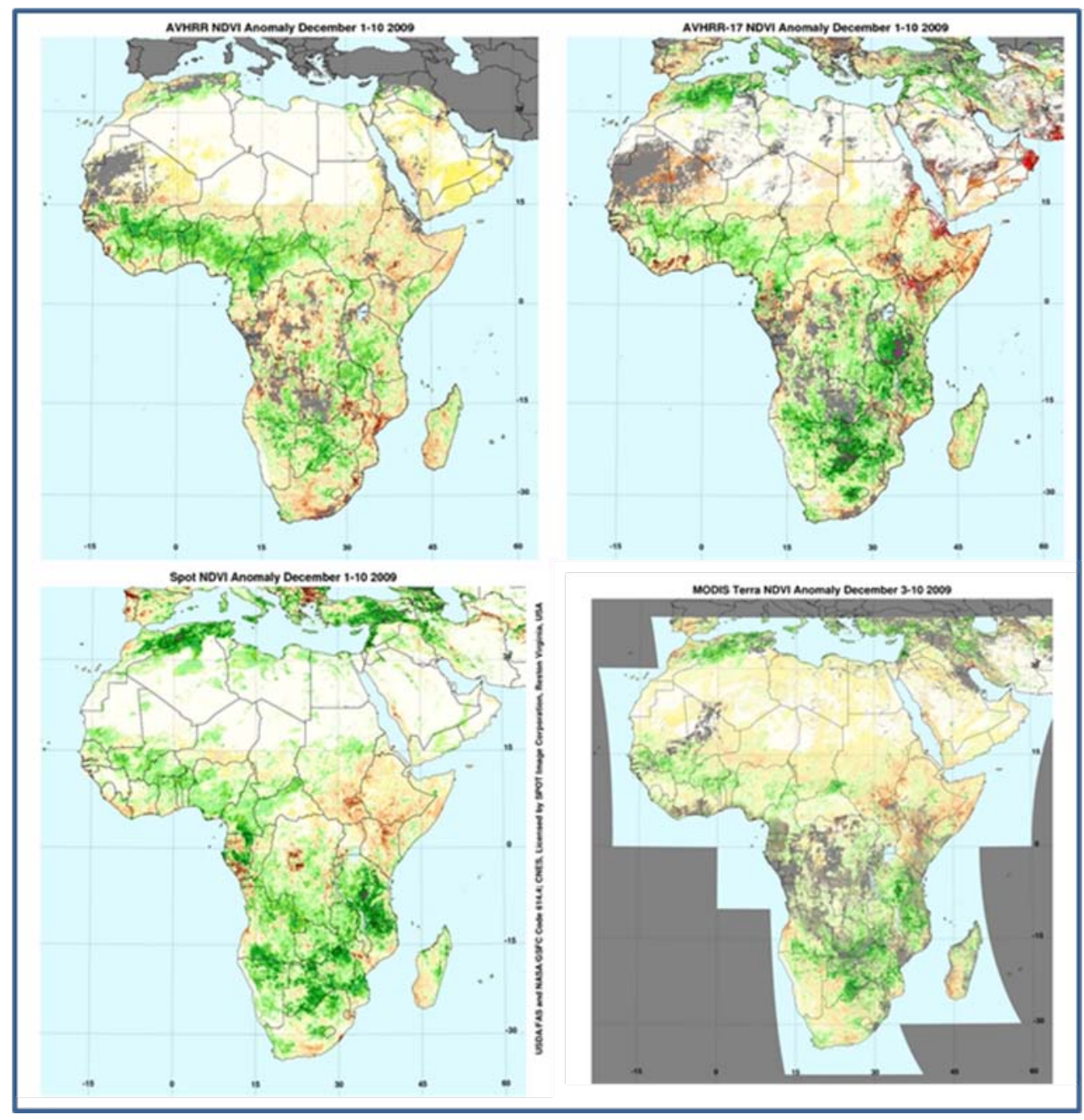




\subsection{New Developments: Operational Research and Development}

A critical component of the GLAM effort is operational research and development, where fundamental remote sensing research can be adapted for potential operational use within the FAS DSS system. A process has been developed whereby user-driven products are prototyped and developed for FAS analyst use. Once developed these prototypes are evaluated and, after feedback and approval, are integrated into the operational FAS system. Currently under evaluation are new near real time surface reflectance products, very-coarse resolution BRDF-corrected vegetation index time-series, and value added products such as cropland masks.

\subsubsection{Near Real Time Surface Reflectance Products}

Data delivery timeliness is one of the key requirements for an effective agricultural monitoring system. The data delivery lag time for the MODIS science VI products generally ranges between 3 and 12 days after the last day of composite. This lag is a significant concern to the FAS DSS, as reporting is made routinely on the 11th day of every month and often the most recent data are not available in time.

In an effort to address this issue the GLAM team has designed and built a new Near-Real-Time (NRT) FAS system. The primary goals of this system are to: increase the timeliness of data delivery to within 24 hours of the last day of the composite and to transition new MODIS science team products into operations. This system ingests and processes daily MODIS NRT surface reflectance data from the new NASA Land Atmosphere Near real-time Capabilities for EOS (LANCE) system. These data are then composited into 16- and 8-day composites, reprojected, mosaicked into the FAS regions of interest, and integrated into the FAS Crop Explorer web-interface within 24 hours of the last day of the compositing period. Once the official MODIS science NDVI composite becomes available (3-12 days after the end of the compositing period) the NRT composite is replaced by the official science product. In this way FAS analysts are guaranteed to have access to timely data until the time that the official science product is available. In order to ensure a close working relationship with the NASA MODIS science team, and to ensure optimal data processing timeliness, this FAS system is co-located with the NASA MODIS Data Processing System (MODAPS) at GSFC.

Currently this new FAS system is in a testing phase. The quality of the NRT 16-day and 8-day composites are being evaluated and assessed for compatibility with the official MODIS science products currently used by the FAS analysts.

One of the goals of the NASA Applications Program is to build on previous NASA science investments, to develop and test new technologies and capabilities with operational partners and then to have the operational partners assume the operation and ownership of the system. Therefore, once the FAS NRT System evaluation is complete, it will be transitioned into an operational system that will be fully owned and operated by the FAS. It is intended that this system will provide a basis for building a long-term FAS operational system that will deliver science quality data from the NPOESS Preparatory Project Visible Infrared Imaging Radiometer Suite (VIIRS). 


\subsubsection{BRDF-Corrected Very-Coarse Resolution Time-Series}

Recently, a new, daily-updated, BRDF corrected, surface reflectance data set from MODIS (at 0.05 degree resolution, equivalent to $5.5 \mathrm{~km}$ at the equator) has been developed by GLAM team members [20], which can potentially enable reliable daily monitoring of agricultural regions. This time-series data set is currently being prototyped to be integrated into the FAS DSS system for crop analyst evaluation.

This is a daily updated product which means that clear, high quality pixels are identified daily, and cloudy, low quality pixels are flagged and replaced by linearly interpolated values until high-quality data become available. In this way, this dataset preserves all of the useable data rather than just a single data point selected by the compositing procedure.

This daily-updated surface reflectance should be able to preserve the temporal signal over cropped areas better than the corresponding standard composite products. As such it is expected that this new product will provide enhanced visualization products and enhanced time-series graphs presenting an improvement over the 16-day and 8-day based time-series graphs, both in terms of graph detail and accuracy which will translate into an improved capability to monitor crop development and condition at coarse scale as the season progresses.

An example below depicts the recent severe drought that affected the Fertile Crescent region of Iraq, Syria and Turkey during the 2008 growing season. Figure 5a shows an NDVI departure from mean image from the 16-day MODIS NDVI data. Areas in brown are indicative of lower than average NDVI values. Figure $5 b$ shows a similar anomaly image from the daily BRDF corrected data. Both images exhibit identical patterns. Figure 5c shows the BRDF-corrected NDVI image from April 14th, 2008, and Figure 5d. shows the mean NDVI for April 14, 2008. The extent and impact of the drought is illustrated by this pair of images. In order to estimate the impact of this drought on production, FAS crop analysts utilize the GLAM 16-day NDVI time series archive and analysis tools to track crop development and to asses crop stress. Currently analysts primarily rely on 16-day composite data. With the addition of the new daily composites, analysts would have access to daily data, which would allow for better characterization of vegetation development, albeit at a coarse scale. This point is illustrated in the graphs in Figure 6. Three crop sites were selected in Iraq's Ninwa province, Syria's Al Hasakah province, and Turkey's Sonlimfa district. The graphs depict the NDVI time-series data from January 2000 through July 2008 for one 0.05 degree CMG pixel within each crop site. The blue points are from the daily BRDF data and the pink points are from the 16-day composite data. Both the pink and blue graphs show very similar patterns of crop phenology, though the blue graphs are able to depict phenology development in a more clear and detailed fashion than the pink graphs. 
Figure 5. A comparison between the 16-day composite data and the daily, BRDF corrected data for Northern Iraq and Syria. Figure 5a-b show NDVI departure from mean (a) the 16-day MODIS NDVI data (b) from the daily BRDF corrected NDVI data. Areas in brown are indicative of lower than average NDVI values. Figure $5 c$ shows the BRDF-corrected NDVI image from April 14th, 2008, and Figure 5d shows the mean NDVI for April 14, 2008. Selected crop sites marked with ' $X$ ' on images (a) and (d).
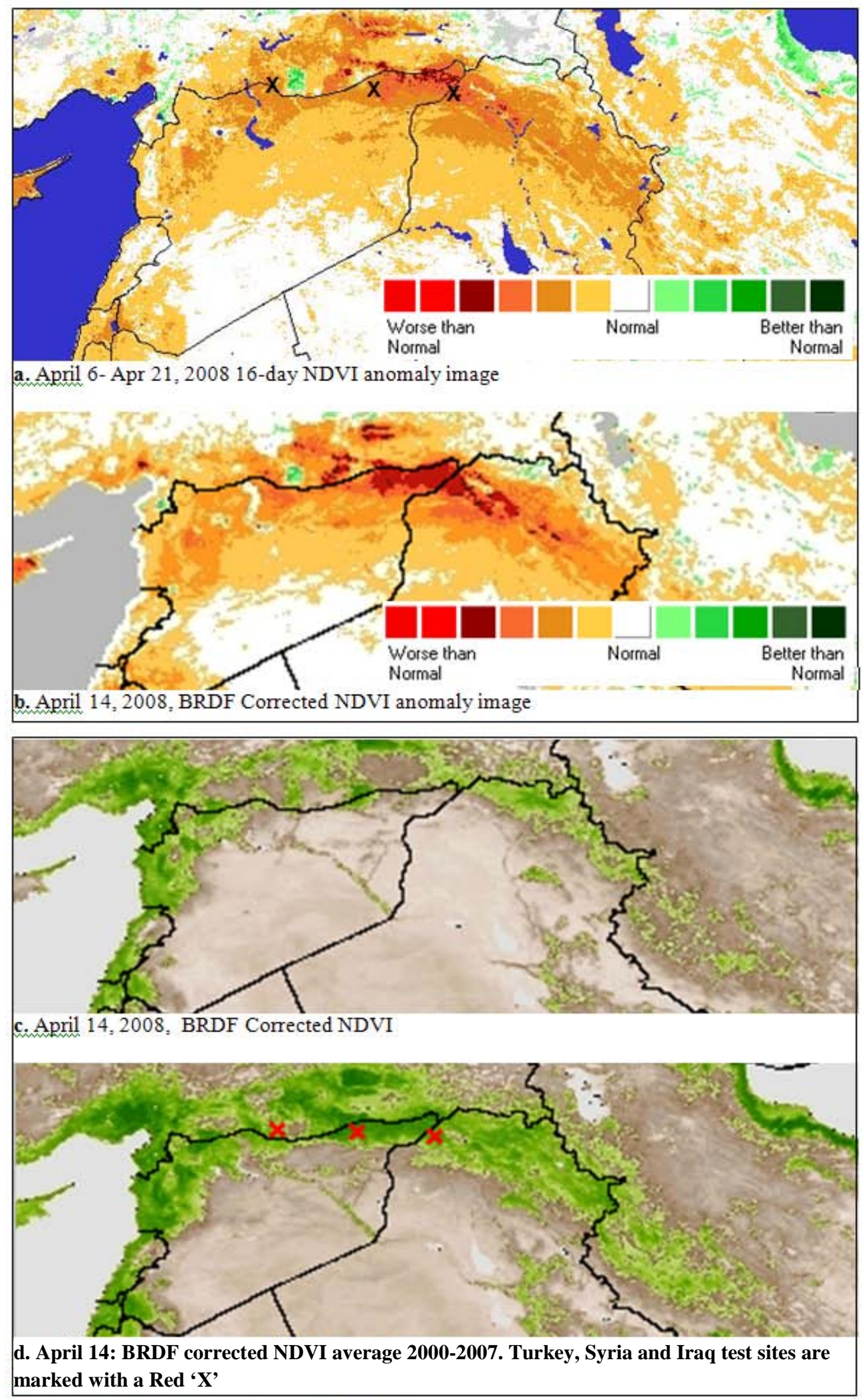
Figure 6. Comparison of 16-day Composite NDV (pink)I with Daily BRDF Corrected NDVI (blue) for 3 Crop sites in Iraq, Syria and Turkey. Both the pink and blue graphs show similar crop phenology though crop development is more clearly depicted in the blue, daily BRDF corrected graph.

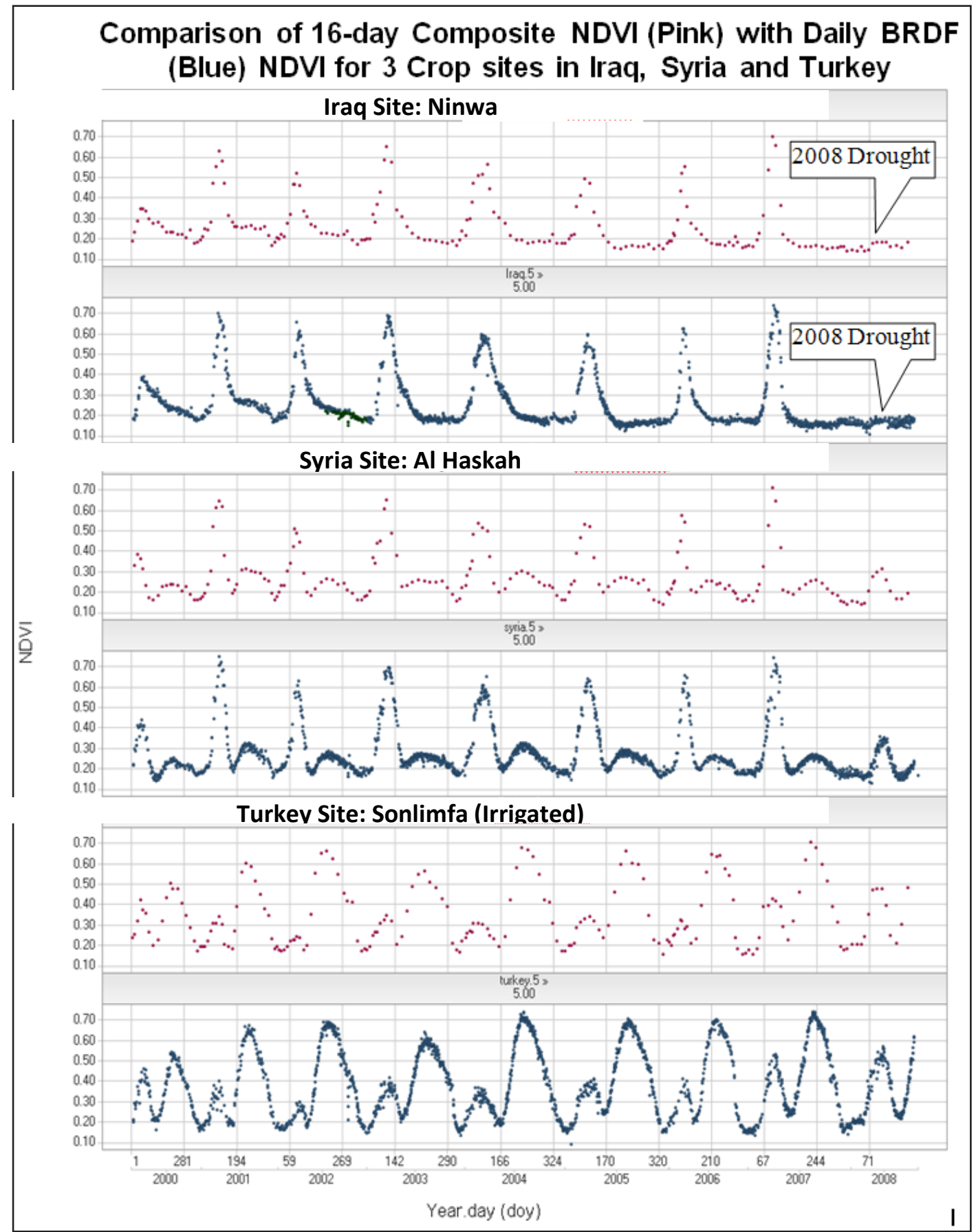

2.4.3. New Value Added Products under Evaluation

To enhance the GLAM system crop condition monitoring and analysis capabilities, a number of value added products are being developed in response to FAS needs. These products include a global croplands map, enhanced vegetation index metrics and analysis tools and lake and reservoir height monitoring products. The intention is to integrate these new products into the operational FAS system once their quality and utility for crop monitoring are assessed. 


\subsubsection{Global Croplands Map}

Recognizing the importance of identification of croplands for monitoring crop development and for production assessment, a dynamic global croplands map at 250-m resolution has been developed in order to map cropland extent (Figure 7) [21]. Once validated, this global cropland mask will be integrated into the CropExplorer time-series web interface and used to interactively spatially filter regional NDVI time-series trends. To develop the cropland product, MODIS 250-m data were used to map the per-pixel probability of global croplands over the time period 2000-2008. A set of 39 multi-year MODIS metrics incorporating four MODIS land bands (Red, NIR, SWIR(5) and SWIR(7)), NDVI and thermal data was generated to capture generic cropland phenology across the time window, as well as remove cloud cover and other atmospheric contamination. A variety of datasets were employed to generate a global training dataset (including the Geocover Land Cover product, AfriCover, and the USDA NASS Cropland Data Layer), covering approximately $80 \%$ of the earth's land surface, excepting Antarctica. These training data were used to derive a set of global classification tree models using a bagging methodology as described in Breiman [22] to assign a crop probability to each MODIS pixel.

As this product was produced for use by USDA FAS, the USDA-FAS Production, Supply and Distribution database of per-country harvested acreage of production field crops (barley, corn, cotton, oats, rice, rye, sorghum, soybeans and wheat) was used to threshold the continuous crop probabilities in order to create a discrete cropland/not cropland classification. Per country thresholds were calculated to create the global map. Pixels labeled as cropland totaled approximately 919 million hectares, a total $2.8 \%$ higher than the FAS global cropland area. The cropland extent mask will be available for FAS analysts to interactively filter growing season cropland phenologies in the respective regional agricultural production centers using the GLAM interface. For the purposes of the GLAM project the USDA FAS harvested area statistics were used to threshold the probability layer, though this probability layer is publically available and can be thresholded according to user needs to produce a variety of cropland extent realizations.

Because the thresholds were applied per country, it was possible to quantify the global result at national and regional levels, as well as looking at thresholds across areas containing the same dominant crop type. For the purposes of regional validation, every country in the world was grouped into one of 13 regions. Among those 13 are 8 single-nation regions representing the largest agricultural producers: Argentina, Australia, Brazil, Canada, China, India, Russia and the United States. Overall the model performed very well in the large industrial agriculture areas, particularly those with corn, soybeans or cotton as dominant crop types. It performed less well in rice-dominated countries, due in part to the lack of training in Southeast Asia, and in low cropland intensification regions such as sub-Saharan Africa.

The new crop map concept provides a method for developing an annual customizable cropland extent map, as well as for developing an annual crop type map, which are both currently unavailable to the FAS and to the agricultural monitoring community at large. A detailed description of the methods and validation of this cropland product can be found in Pittman et al. [21] in this issue. 
Figure 7. Dynamic 250 m Global Croplands Map.

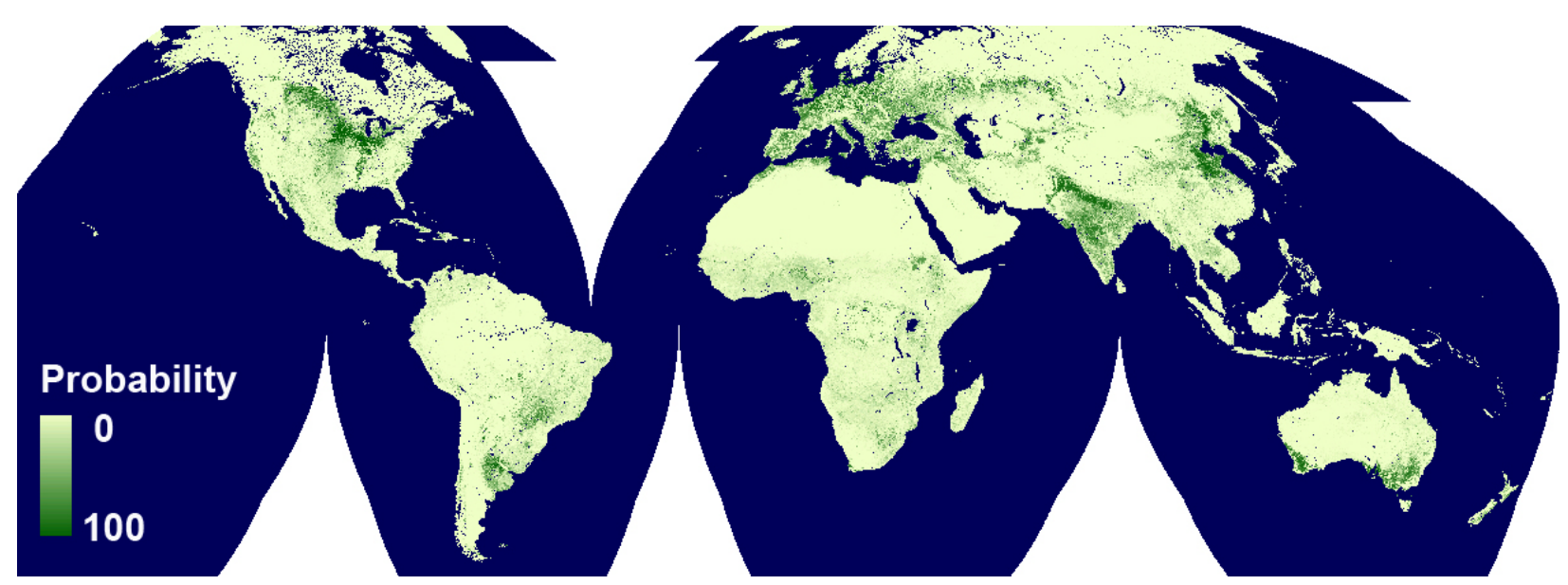

\subsubsection{Enhanced Vegetation Index Products}

Several new products are currently in development for enhanced crop monitoring. The first of these is a cumulative vegetation index (CVI). The CVI is simply the sum of NDVI from the start of the growing season to present, and was developed to allow improved monitoring of crops over the entire growing season. The CVI anomaly (Figure 8) measures the difference between the total greenness for the current growing season and the average total greenness over all previous seasons. The CVI anomaly may be used to complement the current 10-day, 15-day and monthly NDVI anomalies; the NDVI anomalies represent the state of croplands during a single compositing period, whereas the CVI anomaly represents the development of crops over the regional growing season where the start and end of the growing season is specified by the crop analyst. An added functionality for the system is in development, which permits the integration of VI values according to a selected phenologic stage or an entire growing season, allowing users to compare crop development for a particular growth stage or season against previous years, as the season progresses. A tool for analog year identification is also being added to the suite of analysis tools. This will allow analysts to determine which seasons most closely resemble each other in terms of their VI dynamics. This information can then be factored into the crop production forecasts. 
Figure 8. Example of November to January CVI anomaly for East Africa. Left: 2006-2007 season, the most recent wetter than average season. Right: 2009-2010, the current seasonal CVI anomaly.
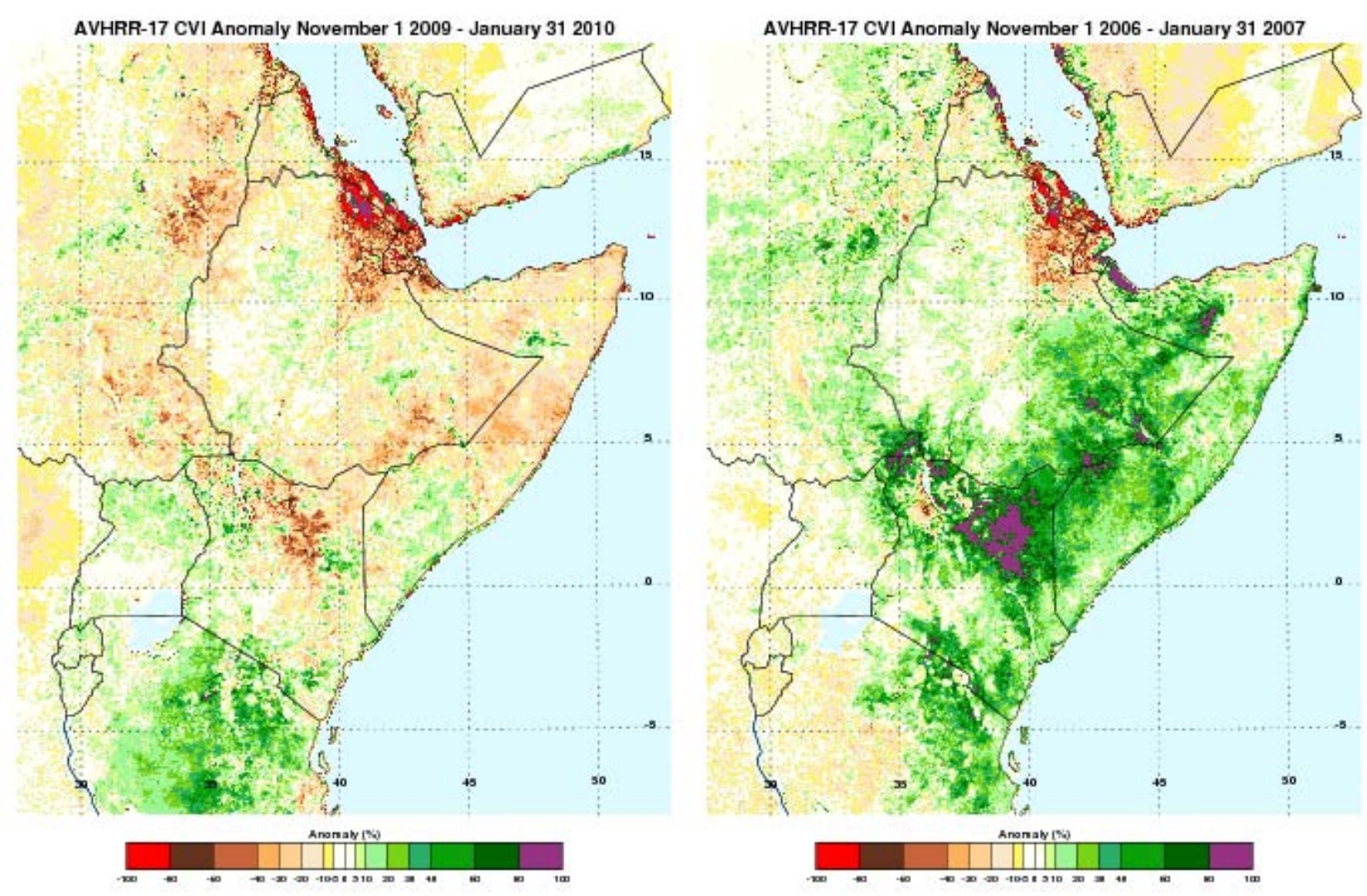

\subsubsection{Global Lake Level Products}

Assessing water availability to crops is of prime importance for monitoring agricultural production. For this purpose a variety of data products including daily weather data from the World Meteorological Organization (WMO) and from the Air Force Weather Agency (AFWA), surface-wetness and snow-depth anomalies derived from the Special Sensor Microwave Imager (SSMI) , and lake and reservoir heights derived from radar altimetry, are currently used within the USDA/FAS DSS.

In many regions of the world, the volume of water stored in lakes and reservoirs can be used as an indicator of irrigation potential, as well as an indicator of short-term droughts and of long-term climatic trends. Due to economic, political and technical reasons, information on water availability for irrigation can be difficult to acquire particularly for water deficit regions which often suffer from poor reporting of such information. Satellite-derived measurements of lake and reservoir surface extent and water level have opened up new possibilities for acquiring such information, and offer an independent resource for monitoring potential irrigation capacity. While the recording of lake area is currently not operational, satellite radar altimetry [23] allows the monitoring of lake or reservoir water levels in the near-real time frame.

Initiated in 2003, the USDA/FAS Global Reservoir and Lake Monitor (GRLM) records variations in surface water height for approximately 70 lakes and reservoirs worldwide using a combination of 
satellite radar altimetry data sets [24]. The project is run in cooperation with NASA/GSFC and the University of Maryland (UMD) and the focus is on the delivery of near-real time products. Currently, products are derived from the NASA/Centre National d'Études Spatiales (CNES) Jason-2/OSTM mission (post 2008), with archival products derived from the NASA/CNES TOPEX/Poseidon mission (1992-2002), the US Naval Research Lab’s (NRL) Geosat follow-on (GFO) mission (2000-2008) and the NASA/CNES Jason-1 mission (2002-2008). Validation exercises show that the products vary in accuracy from a few centimeters rms to several tens of centimeters rms depending on target size and surface wave conditions. On a weekly basis, new satellite data are retrieved and land and reservoir height products are updated. Output products are in the form of graphs (Figure 9) and text files with web links to other imaging and information resources. In the current phase of the program, an expansion to several hundred lake and reservoirs via the incorporation of products derived from the European Space Agency (ESA) remote sensing satellites (ERS-1 and ERS-2, 1992-2008) and the ESA environmental satellite ENVISAT (post 2002) is planned.

The Current and historical surface water height information provided through GLRM assist USDA/FAS crop analysts, as well as FAS attachés, decision-makers, and the global community to monitor reservoir capacities and downstream irrigation potential for major irrigation schemes; monitor short-term regional droughts during crop growing seasons; and monitor long-term climatic trends and droughts that expand time scales ranging from several months to several years in duration. The monitoring system thus has relevance to water resources management and agriculture efficiency at both the national and international level.

Figure 9. Time series of lake level variations for Lake Kariba, Zambia, derived from satellite radar altimeter observations, blue (Topex/Poseidon), red (Jason-1), purple (Jason-2/OSTM) for the 1993-2010 period. Lower plot depicts a filtered version of the actual results (top) for visual inspection only.

Lake Kariba Height Variations

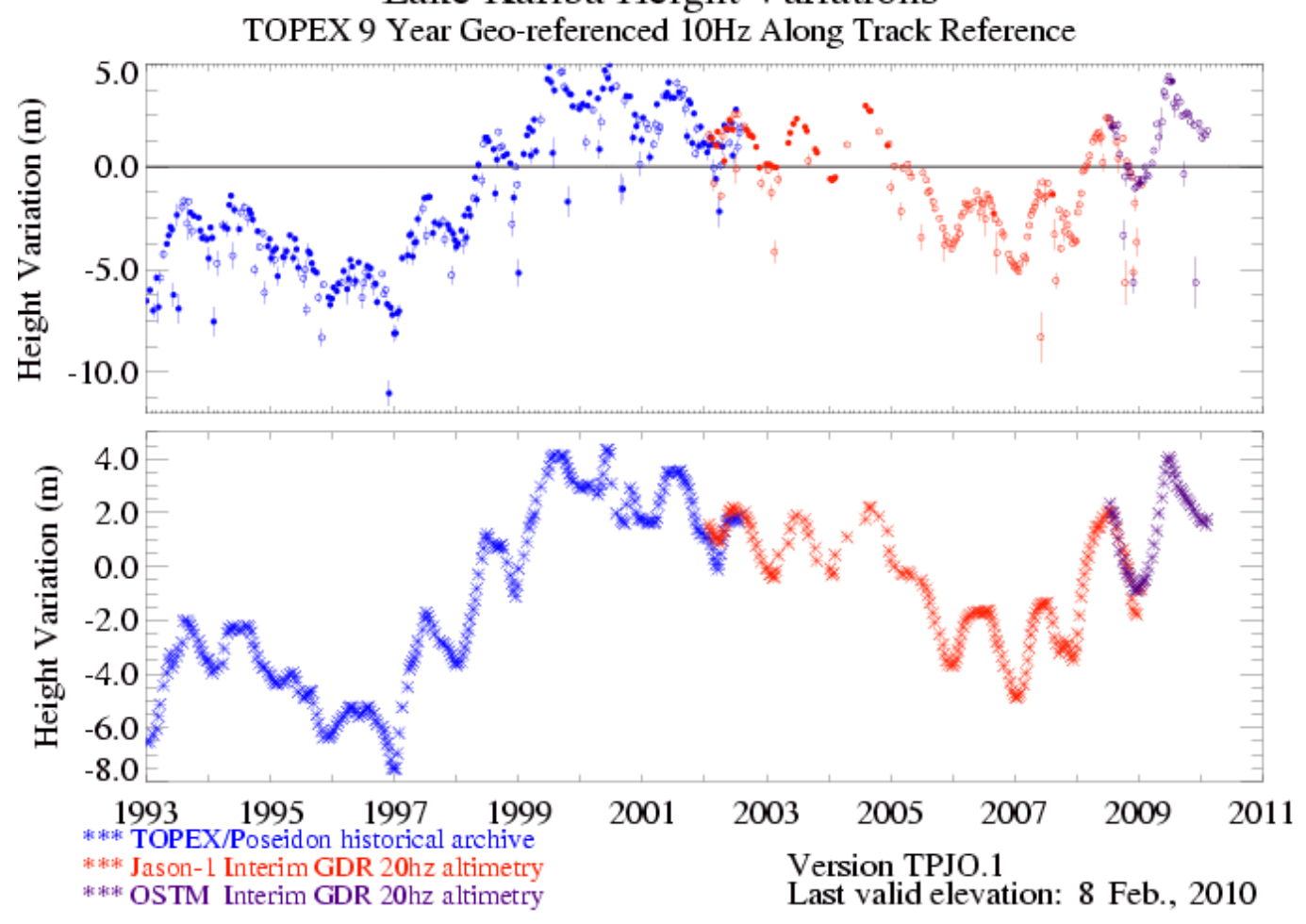




\section{GEO}

The GLAM project is playing leadership role in the Group on Earth Observations (GEO) agricultural monitoring component. Chris Justice of the GLAM team is co-leading the GEO agricultural monitoring task AG-07-03 (www.earthobservations.org/cop_ag_gams.shtml), with Olivier Leo (European Commission Joint Research Center, EC JRC) and Wu Bingfang (Institute for Remote Sensing Applications, IRSA, of the Chinese Academy of Sciences, CAS), bringing together the agricultural monitoring international community.

With the help of the GLAM Project, the GEO Ag 0703 Task has organized a set of well attended, international GEO agriculture monitoring workshops, hosted by the Food and Agriculture Organization (FAO) in Rome, the Chinese Academy of Sciences (CAS) and the EC JRC. The first two workshops held in 2006 and 2007 brought the international community together to form the agricultural community of practice, review the current state of agricultural monitoring, identify the current requirements for earth observation for agricultural monitoring, develop a set of priority recommendations for international coordination and develop the GEO 5-10 year strategy for earth observations in support of agriculture [23]. In addition, the GLAM team is leading the development of a Production Acreage and Yield (PAY) online database. PAY will enable identification of agreements and disagreements between national level crop statistics from the main international agencies which generate agricultural statistics, coordinate international earth observations assets, facilitate capacity building for developing countries, and help complete the CoP's subtasks including developing much needed global cropland products for the benefit of the international community.

Through these GEO GLAM activities, NASA and the USDA, both key partners in the US-GEO and the international GEOSS, are directly contributing to building a GEO agricultural monitoring system and to developing an international long term strategy for agricultural monitoring.

\section{Future Needs and Role of Earth Observations for Agricultural Monitoring}

The need for comprehensive, systematic and accurate global agricultural monitoring is likely to continue to grow in the face of anticipated more frequent and extreme climate events such as floods and drought, increasing energy needs, and increasing demand for food driven by population growth and economic development. The recent 2008 'food crisis' underscores the importance of obtaining global, timely, objective and accurate information on crop conditions and production to guarantee global supply and demand and stabilize prices.

As the FAS crop estimates are the primary source of agricultural market intelligence for US as well as many international decision makers, it is fundamental that the FAS is able to continue to meet these agricultural information demands in a timely reliable manner. The technology and data provided by the GLAM project are helping to ensure that the FAS will continue to meet these growing informational needs. These include timely data delivery, ensuring continuity of earth observing missions particularly at the coarse and moderate resolutions, enhancement of frequency and availability of moderate resolution data (20-60 m), enhanced value added products such as crop type maps, crop calendars, biophysical measures and vegetation indices, enhanced yield models, crop area estimates, and seasonal weather forecasts, inter-operability between the current and future sensors, and better integration across data sets at differing spatial resolutions. 
Although sensing systems are currently available to meet many of the crop monitoring needs, enhancements, particularly at the moderate resolution $(20 \mathrm{~m}-60 \mathrm{~m})$, are urgently needed. Although daily MODIS $250 \mathrm{~m}$ data can be used to monitor areas with very large field sizes, finer resolution data are needed two or three times every 10 days to provide the necessary cloud free coverage for monitoring many of the agricultural regions with smaller field sizes [23]. Until recently, the IRS AWiFS (56 meter resolution and $740 \mathrm{~km}$ swath) was providing 5 to 6 images per month, which offered the frequency of coverage needed for crop monitoring [24,25] but problems with the solid state recorder mean that the data are often unavailable. In contrast, the Landsat 7 (30 meter resolution and $185 \mathrm{~km}$ swath) provides 16 day coverage which is sub-optimal for agricultural monitoring. In addition the instrument was severely impacted by a scan line corrector malfunction in 2003 and is no longer used for crop monitoring. The Landsat Data Continuity Mission, scheduled to launch in 2012, will have an increased global acquisition and processing capability and will provide a new source of data. The aforementioned sensor redundancy is also needed at moderate resolution and there is an urgent need to develop a coordinated global acquisition strategy for the currently available assets (e.g., CBERS, ASTER, SPOT, Landsat 5). The CEOS Land Surface Imaging Constellation (LSI) is being tasked by the GEO Agricultural Monitoring task to provide 2-3 scenes every 10 days at resolutions between $20 \mathrm{~m}$ and $60 \mathrm{~m}$. This strategy should be extended into the future and applied to the constellation of next generation sensors at this resolution as they come online (e.g., CBERS 3, Resourcesat 2, LDCM, Sentinel 2) and, ultimately, to global acquisitions at 10m. Similarly, a strategy is needed to acquire one or two images a month at $5 \mathrm{~m}-1 \mathrm{~m}$, sampling critical agricultural areas. In addition there is a need to explore and enhance methods for the integrated use of coarse and moderate resolution data for agricultural monitoring which can be used in tandem both for crop area estimation as shown by Chang et al. [26] and for crop condition monitoring.

At present, the coarse scale observations $(1 \mathrm{~km}-250 \mathrm{~m})$ are sufficient to meet the agricultural monitoring needs of the FAS, assuming that, at a minimum, the VIIRS instrument on NPP is successfully launched. The NPOESS Preparatory Project (NPP) VIIRS instrument will extend the NASA MODIS data record and will be continued by the operational NPOESS. EUMETSAT will continue to operate an AVHRR on METOP, their morning platform. The prospect for the long term provision of operational coarse resolution data over the next decade is ensured with these planned missions that will provide daily coarse resolution observations. Additional planned coarse resolution systems such SGLI (Japan) and Sentinel-3 (ESA) will provide additional capabilities and the desired redundancy to compensate for any sensor degradation or system failures. Attention also needs to be given to ensuring data product continuity and quality assurance, requiring instrument calibration and inter-calibration, product inter-comparison and validation. Data continuity between instruments can be facilitated by a consistent central wavelength and bandwidth for the core visible to shortwave vegetation monitoring bands.

\section{Conclusions}

At a time when food supply and security are a major national concern, the GLAM project is improving the USDA FAS capabilities for global agricultural monitoring, providing critical information in a timely manner for crop condition assessment and production forecasting. The primary goals of this collaborative project are to continue to advance the USDA FAS Decision Support System 
with NASA data and expertise, establish a USDA Data Processing System at NASA GSFC, and prototype the operational pathway for data from NPOESS VIIRS to ensure operational, long-term data continuity for FAS. These goals are being achieved through the provision of timely, reliable, high-quality earth observations data that are composited and mosaicked according to the FAS regions of interests; an extensive and consistent MODIS Vegetation Index data archive which enables analysts to perform quantitative analysis for crop condition assessment and yield forecasting; long-term data archives of AVHRR and SPOT VI data; a variety of customized data analysis tools which allow analysts to query and aggregate the time series data according to sub-national units and analyst-specified areas; crop masks that are integrated into the analysis tools; and MODIS rapid response data, available twice daily within four hours of overpass. These dataset and tools are easily accessible to FAS analysts as they are seamlessly integrated into the FAS DSS. The intention of the GLAM project is to continue the long term partnership through which data and techniques developed in the NASA research domain are transitioned into a fully operational domain operated by USDA. In addition, given the expertise in agricultural monitoring developed through this long-term NASA-USDA relationship, the GLAM project is in a position to provide international leadership on global agricultural monitoring through the GEOSS Task Ag 0703, strengthening the international Community of Practice and making wide use of NASA's satellite assets and USDA expertise and in turn increasing access to and use of data from international space-borne assets.

\section{Acknowledgements}

The Global Agricultural Monitoring Project is made possible through funding provided by the NASA Applied Science Program and the USDA Foreign Agricultural Service, grant code NNS06AA03A.

\section{References}

1. Justice, C.; Becker-Reshef, I.; Parihar, J.S.; DeLince, J.; Leo, O.; Binfang, W.; Defourny, P.; Townshend, J.T.; Fan, J. The GEO Global Agricultural Monitoring System of Systems Task: An overview. In 33rd International Symposium on Remote Sensing of Environment, ISRSE: Stresa, Italy, May 2009.

2. UN FAO. Assessment of the World Food Security; Report by the Committee on World Food Security from the Thirty First Session; FAO, UN: Rome, Italy, 2005.

3. Becker-Reshef, I.; Justice, C.; Doorn, B.; Reynolds, C.; Anyamba, A.; Tucker, C.J. NASA’s contribution to the Group on Earth Observations (GEO) Global Agricultural Monitoring System of Systems. NASA Earth Observer 2009, 21, 24-29.

4. Macdonald, R.B.; Hall, F.G. Global crop forecasting. Science 1980, 208, 670-679.

5. Pinter, P.J.; Ritchie, J.C.; Hatfield, J.L.; Hart, G.F. The agricultural research service's remote sensing program: An example of interagency collaboration. Photogramm. Eng. Remote Sensing 2003, 69, 615-618.

6. Knipling, E.B. Physical and physiological basis for the reflection of visible and near-infrared radiation from vegetation. Remote Sens. Environ. 1970, 1, 155-159. 
7. Leamer, R.W.; Weber, D.A.; Wiegand, C.L. Pattern recognition of soils and crops from space. Photogramm. Eng. Remote Sensing 1975, 41, 471-478.

8. Allen, W.A.; Richardson, A.J. Interaction of light with a plant canopy. J. Opt. Soc. Amer. 1968, 58, 1023-1028.

9. Hatfield, J.L.; Gitelson, A.A.; Schepers, J.S.; Walthall, C.L. Application of spectral remote sensing for agronomic decisions. Agron. J. 2008, 100, S117-S131.

10. Bauer, M.E. LACIE: An experiment in global crop forecasting. Crops Soils Mag. 1979, 31, 5-7.

11. USDA. A Guide to USDA's International Programs; USDA, 2007. Available online: www.csrees.usda.gov/nea/international/pdfs/vis_guide.pdf (accessed on January 23, 2010).

12. USDA FAS. The Foreign Agricultural Service. Available online: http://www.fas.usda.gov/aboutfas.asp (accessed on January 23, 2010).

13. Reynolds, C.A. Input data sources, climate normals, crop models, and data extraction routines utilized by PECAD. In Third International Conference on Geospatial Information in Agriculture and Forestry, Denver, CO, USA, 2001.

14. USDA FAS. GLAM-Global Agricultural Monitoring. Available online: http://www.pecad.fas.usda.gov/glam.cfm (accessed on December 28, 2009).

15. Kaupp, V.; Hutchinson, C.; Drake, S.; Haithcoat, T.; Leeuwen, W.V.; Likholetov, V.; Tralli, D.; Doorn, B. Benchmarking the USDA OGA DSS: A PECAD Update; Washington, DC, USA, 2007.

16. Vermote, E.F.; El Saleous, N.Z.; Justice, C.O. Atmospheric correction of MODIS data in the visible to middle infrared: first results. Remote Sens. Environ. 2002, 83, 97-111.

17. USDA FAS. World Agricultural Production. Bange, G., USDA World Agricultural Outlook Board; Williams, D., Eds. Available online: http://www.fas.usda.gov/wap/circular/2009/ 09-01/productionfull01-09.pdf (accessed on January 23, 2010).

18. Justice, C.O.; Giglio, L.; Korontzi, S.; Owens, J.; Morisette, J.T.; Roy, D.; Descloitres, J.; Alleaume, S.; Petitcolin, F.; Kaufman, Y. The MODIS fire products. Remote Sens. Environ. 2002, 83, 244-262.

19. Tucker, C.J.; Pinzon, J.E.; Brown, M.E.; Slayback, D.A.; Pak, E.W.; Mahoney, R.; Vermote, E.F.; El Saleous, N. An extended AVHRR 8-km NDVI dataset compatible with MODIS and SPOT vegetation NDVI data. Int. J. Remote Sens. 2005, 26, 4485-4498.

20. Vermote, E.; Justice, C.O.; Breon, F.M. Towards a Generalized Approach for Correction of the BRDF Effect in MODIS Directional Reflectances. IEEE Trans. Geosci. Remote Sens. 2009, 47, 898-908.

21. Pittman, K.W.; Hansen, M.C.; Becker-Reshef, I.; Potapov, P.V.; Justice, C.O. Estimating global cropland extent with multiyear MODIS data. Remote Sens. 2010, submitted.

22. Breiman, L. Bagging predictors. Mach Learn 1996, 24, 123-140.

23. Justice, C.; Becker-Reshef, I. Report from the Workshop on Developing a Strategy for Global Agricultural Monitoring in the framework of Group on Earth Observations (GEO) 16-18 July 2007, FAO, Rome; University of Maryland: College Park, MD, USA, 2007.

24. Oza, M.P.; Pandya, M.R.; Rajak, D.R. Evaluation and use of Resourcesat-1 data for agricultural applications. Int. J. Appl. Earth Obs. Geoinf. 2008, 10, 194-205.

25. Sai, M.V.R.S.; Rao, P.V.N. Utilization of Resourcesat-1 data for improved crop discrimination. Int. J. Appl. Earth Obs. Geoinf. 2008, 10, 206-210. 
26. Chang, J.; Hansen, M.C.; Pittman, K.; Carroll, M.; DiMiceli, C. Corn and soybean mapping in the united states using MODN time-series data sets. Agron. J. 2007, 99, 1654-1664.

(C) 2010 by the authors; licensee MDPI, Basel, Switzerland. This article is an Open Access article distributed under the terms and conditions of the Creative Commons Attribution license (http://creativecommons.org/licenses/by/3.0/). 